\title{
Effect of vitamin D status on normal fertilization rate following in vitro fertilization
}

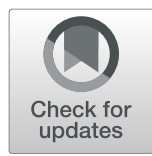

\author{
Xuemei Liu ${ }^{1 *}\left(\mathbb{D}\right.$, Wei Zhang ${ }^{1 \dagger}$, Yanping $\mathrm{Xu}^{1 \dagger}$, Yongli $\mathrm{Chu}^{2}$, Xinrong Wang ${ }^{1}$, Qian $\mathrm{Li}^{3}$, Zhi Ma ${ }^{1}$, Zhenteng Liu \\ and Yanling Wan'
}

\begin{abstract}
Background: Vitamin D plays critical role in the female reproductive system. It seems that vitamin D is associated with clinical pregnancy outcomes of assisted reproductive technologies (ART), but its role remains elusive. This study is aimed to establish whether vitamin $D$ is associated with clinical outcomes of in vitro fertilization (IVF).

Methods: The cross-sectional study was carried out from January 1st 2017 to December 31st 2017. A total of 848 patients who had indications for IVF were enrolled. The patients were classified by serum $25(\mathrm{OH}) \mathrm{D}$ quartiles. The outcome parameters of IVF were compared in each group, including normal fertilization rate, high quality embryo rate, clinical pregnancy rate, implantation rate and live birth rate.

Results: The median $25(\mathrm{OH})$ D concentration was $15.25 \mathrm{ng} / \mathrm{ml}$. Serum $25(\mathrm{OH})$ D levels in women varied with the seasons. We found that serum $25(\mathrm{OH}) \mathrm{D}$ levels were higher in autumn than other seasons, and the lowest level occurred in spring. Follicular fluid (FF) vitamin D levels were positively correlated with serum vitamin D levels $(r=0.85, P<0.001)$. The levels of FF vitamin $\mathrm{D}$ were significantly higher than the levels of serum vitamin $\mathrm{D}(P<0.001)$. Normal fertilization rates were significantly different among four groups $(P=0.007)$. The group of women with the highest serum $25(\mathrm{OH}) \mathrm{D}$ levels had the highest normal fertilization rate. However, the clinical pregnancy rate, implantation rate and live birth rates were not significantly different among the four groups when the age, $\mathrm{BM}, \mathrm{AMH}$, seasons of blood drawing, $\mathrm{COH}$ protocol, high quality embryo rate and number of embryos transferred were adjusted. In addition, we found that serum $25(\mathrm{OH}) \mathrm{D}$ levels were significantly higher in patients received IVF than patients received R-ICSI $(P=0.013)$.
\end{abstract}

Conclusions: Among Chinese women, lower serum vitamin D levels are associated with a lower fertilization rate in IVF. However, vitamin D level was not associated with the clinical pregnancy and live birth rate following IVF.

Keywords: Vitamin D, Clinical pregnancy rate, Live birth rate, In vitro fertilization

\section{Background}

Vitamin D is a fat-soluble steroid hormone. It has an important role in Calcium-Phosphate (Ca-P) homeostasis and bone metabolism $[1,2]$. Vitamin D comes mainly from sunlight. Only a small amount comes from diet. Vitamin D deficiency has been emerging in recent two decades among all racial groups [3]. Vitamin D insufficiency is endemic because of poor sunlight exposure, lifestyle, use of sunscreens, low dietary intake, and/or increased body mass index (BMI) $[4,5]$. Vitamin D deficiency has been considered a public health problem in all over the world. Low vitamin D

\footnotetext{
* Correspondence: xuemeiliu02@yeah.net

†Xuemei Liu, Wei Zhang and Yanping Xu contributed equally to this work.

${ }^{1}$ Reproductive Medicine Center, Yantai Yuhuangding Hospital, Affiliated

Hospital of Qingdao University, Yantai, Shandong, China

Full list of author information is available at the end of the article
}

concentrations have been associated with an increased risk of many chronic diseases, including autoimmune disease, diabetes, cardiovascular disease, obesity and cancer [6]. Recently, poor vitamin D status verified in $20-52 \%$ of women of reproductive years, suggests that vitamin $\mathrm{D}$ has an important role in female reproduction [7-9].

Vitamin D exerts effect by binding with the nuclear vitamin D receptor. Vitamin D receptors have been identified in many tissues, including the ovary, uterus, placenta and the pituitary [10]. These data indicate that vitamin D may be an important regulator of the reproductive system. The importance of vitamin D in reproduction is evident from animal studies. Vitamin D deficiency could cause uterine hypoplasia, reduced fertility, hypogonadism and impaired folliculogenesis $[1,11-13]$. In humans, vitamin $\mathrm{D}$ has an important 
role in placental function [14]. Vitamin D deficiency is associated with poor placentation, fetal growth restriction, gestational hypertension and pre-eclampsia [14]. In addition, vitamin D plays critical role in oocyte development, ovarian steroidogenesis, production of anti-Mullerian hormone $(\mathrm{AMH})$, endometrial receptivity, and others $[15,16]$. It was supposed that vitamin $\mathrm{D}$ is associated with clinical outcomes of assisted reproductive technologies (ART).

So far, there were many studies investigating the association between vitamin $\mathrm{D}$ level and the clinical outcomes of ART, but the data are inconclusive. Some studies found that vitamin D could improve the outcomes of ART [1724]. In contrast, other studies reported that vitamin D has no effect on the outcomes of ART [25-30]. Hence, the role of vitamin D in ART is still unclear. To solve this problem, we set up a large retrospective cross-sectional study to evaluate the association between serum levels of $25(\mathrm{OH}) \mathrm{D}$ and outcomes of ART in Chinese women.

\section{Methods}

Trial design and participants' characteristics

This was a retrospective cohort study. We have retrospectively reviewed the data of all patients, who underwent their in vitro fertilization (IVF) cycle at Yantai Yuhuangding Hospital from January 1st 2017 to December 31st 2017. The study protocol was approved by the Ethical Committee of Yantai Yuhuangding Hospital. The study conformed to the "Declaration of Helsinki for Medical Research involving Human Subjects". Patient characteristics and cycle parameters were obtained from patient medical records.

Only one IVF cycle of each patient was selected within the study time frame. None of the patients received vitamin D supplements. Patients were excluded if they were diagnosed with premature ovarian in sufficiency or if they were treated with intracytoplasmic sperm injection (ICSI) or rescue ICSI (R-ICSI). To avoid confounders, women whose plasma total $25(\mathrm{OH})$ D measurements exceeded 4 weeks prior to entering their IVF cycle were excluded from the study, since the season impacts on the serum $25(\mathrm{OH})$ D concentrations in Yantai.

\section{Procedure of IVF}

All patients undergoing IVF cycles receive luteal phase gonadotrophin-releasing hormone $(\mathrm{GnRH})$ agonist protocol or $\mathrm{GnRH}$-antagonist protocol. In luteal-phase gonadotrophinreleasing hormone $(\mathrm{GnRH})$ agonist protocol, low- or regulareuprolide was used to make pituitary desensitization beginning in the luteal phase. In GnRH-antagonist protocol, GnRH-antagonist ganirelix was used when the dominant follicle reached $12 \mathrm{~mm}$ in diameter, estradiol concentrations were $>150 \mathrm{pg} / \mathrm{ml}$ and/or luteinizing hormone concentrations were $>10 \mathrm{IU} / \mathrm{L}$. During gonadotrophin stimulation, serum estradiol, progesterone and luteinizing hormone, follicle size measurements, and endometrial thickness were monitored until the day of human chorionic gonadotropin (hCG) trigger injection. When two leading follicles reached a mean diameter of $18 \mathrm{~mm}$, hCG was given to trigger ovulation. Oocytes were retrieved transvaginally $34-36 \mathrm{~h}$ after hCG administration. IVF was performed. Ultrasound-guided fresh embryo transfer was performed on the third day after oocyte retrieval, and excess viable embryos were cultured to blastocyst stage and cryopreserved for subsequent frozen embryo transfer (FET) cycles. The number of embryos transferred was one or two depending on the number of available embryos. Fresh embryo transfer was cancelled if the embryo and endometrium were not synchronous or women had a high risk of ovarian hyperstimulation syndrome and factors seriously affecting embryo implantation. The obtained embryos were graded depending on published criteria [31]. The embryos of grade 1 or 2 were considered as high-quality embryos. The luteal phase was supported with $200 \mathrm{mg}$ progesterone (Utrogest ${ }^{\mathrm{tix}}$ 200, Besins-Iscovesco, France) vaginal medication three times daily from the day of oocyte retrieval. A quantitative pregnancy test (serum $\beta$-hCG based) was performed on the 14th day after embryo transfer. In terms of pregnancy, a transvaginal ultrasound was performed after 4 weeks from the embryo transfer. Clinical pregnancy was confirmed if the fetal heartbeat was observed by transvaginal ultrasound. Live birth was defined as the birth of a neonate.

\section{Serum $25(\mathrm{OH}) \mathrm{D}$ measurement}

Total $25(\mathrm{OH}) \mathrm{D}$ was measured before entering IVF cycle. The measurement of total $25(\mathrm{OH}) \mathrm{D}$ levels was performed using a chemiluminescence immunoassay (DiaSorin). The intra- and inter- assay coefficients of variations were 10 and $15 \%$, respectively.

\section{Serum and follicular fluid (FF) collection and $25(\mathrm{OH}) \mathrm{D}$ measurement}

Sixty-two serum samples were obtained on the oocyte retrieval day and were kept frozen at $-80^{\circ} \mathrm{C}$. FF had been also collected from the same 62 patients. FF aspiration was performed from the first follicle on oocyte retrieval day. FF was centrifuged at $3000 \mathrm{~g}$ for $10 \mathrm{~min}$. The supernatant was stored at $-80^{\circ} \mathrm{C}$ for subsequent assay. Serum and FF $25(\mathrm{OH}) \mathrm{D}$ levels were measured by a chemiluminescence immunoassay (DiaSorin).

The levels of serum vitamin D varied significantly in different seasons because of the different exposure to sunlight (Additional file 1: Table S1) [32]. Therefore, the season of blood drawing was included in the study. Each season lasted 3 months: Spring: February 1-April 30; Summer: May 1July 31; Autumn: August 1-October 31; Winter: November 1-January 31.

\section{Study design}

All patients were assigned to quartiles depending on the levels of vitamin $\mathrm{D}$ before entering the IVF cycle. The 
demographic and reproductive characteristics were calculated by descriptive statistics according to quartiles of vitamin $\mathrm{D}$ concentrations. We evaluated the association of serum $25(\mathrm{OH}) \mathrm{D}$ concentrations in quartiles and treatment outcomes of IVF cycle while adjusting for potential confounding factors.

\section{Main outcome measures}

The primary outcome was clinical pregnancy rate. It was defined as the presence of an intrauterine sac confirmed by ultrasound at 6 weeks of gestation. Secondary outcomes were: live birth rate, implantation rate and (2 PN) fertilization rate.

\section{Statistical methods}

The continuous variables were presented as mean \pm $\mathrm{SD}$, and the proportions were presented as percentages. The Kruskal-Wallis test was used for continuous variables. The chi-square test was used for categorical variables.
Receiver operating characteristic (ROC) curves were used to analyze the predictive value of serum vitamin $\mathrm{D}$ levels on clinical pregnancy rate, live birth rate and fertilization rate. Low fertilization rate (LFR) was defined as normal fertilization rate below $30 \%$ as it was a clinical standard for ICSI to promote normal fertilization rate. Spearman's test was used to evaluate the correlation between serum vitamin D levels and FF vitamin D levels.

A univariate and multivariate logistic regression analysis was applied to analyze the relationship of vitamin D and clinical outcomes of IVF. The variables that were evaluated as potential confounders included: age, BMI, $\mathrm{AMH}$, type of infertility, previous pregnancy, seasons when samples were taken, the type of treatment protocol, duration of stimulation, $\mathrm{E}_{2}$ levels on the day of $\mathrm{hCG}$, number of oocytes retrieved, number of mature oocytes, the percentage of top quality embryos, endometrial thickness, serum progesterone levels on the day of hCG and the number of embryo transferred.

The data were analyzed by use of the SPSS-12.0 software. $P<0.05$ was considered to be statistically significant.

\section{4 cycles with the measurement of serum vitamin D}

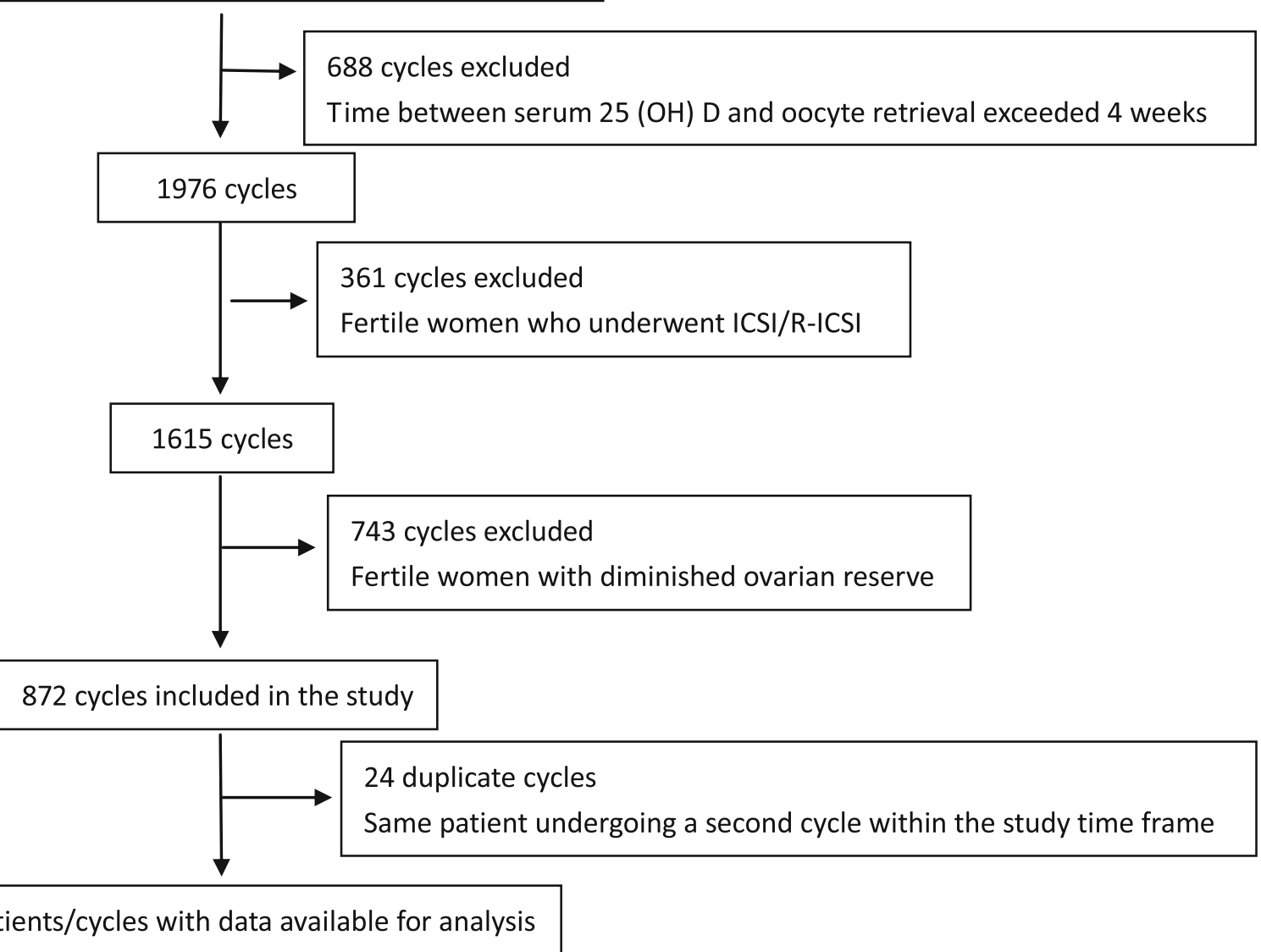

848 patients/cycles with data available for analysis

Fig. 1 Patient selection process 


\section{Results}

Overall, 848 patients were included in this study (Fig. 1). Of the 848 fresh cycles with oocyte retrieval, 487 cycles had fresh embryo transfer. The median (minimum, maximum) $25(\mathrm{OH})$ D concentration was $15.25 \mathrm{ng} / \mathrm{ml}$ (4.92-39.51 ng/ml).

Table 1 depicts patients and IVF cycle characteristics according to serum $25(\mathrm{OH})$ D quartiles. The levels of

Table 1 Patients and IVF cycle characteristics by serum $25(\mathrm{OH})$ D quartiles

\begin{tabular}{|c|c|c|c|c|c|}
\hline Parameter & Group1 & Group2 & Group 3 & Group 4 & $P$ value \\
\hline Number of cycles & 216 & 210 & 211 & 211 & \\
\hline \multicolumn{6}{|l|}{ Serum 25(OH) D (ng/ml) } \\
\hline Median & 9.04 & 13.67 & 16.20 & 23.22 & \\
\hline Range & $4.92-11.20$ & $11.25-14.00$ & $14.10-18.60$ & $18.70-39.51$ & \\
\hline Age(y) & $31.65 \pm 3.32$ & $31.86 \pm 3.94$ & $31.31 \pm 3.44$ & $31.88 \pm 3.69$ & 0.331 \\
\hline Duration of infertility(y) & $3.53 \pm 2.19$ & $3.85 \pm 2.76$ & $3.68 \pm 2.31$ & $3.61 \pm 2.38$ & 0.543 \\
\hline BMI $\left(\mathrm{kg} / \mathrm{m}^{2}\right)$ & $23.93 \pm 3.61$ & $23.37 \pm 3.30$ & $23.16 \pm 3.28$ & $23.46 \pm 3.33$ & 0.099 \\
\hline AMH (ng/ml) & $7.21 \pm 5.50$ & $6.05 \pm 4.37$ & $6.93 \pm 5.61$ & $6.68 \pm 5.51$ & 0.134 \\
\hline $\mathrm{bFSH}(\mathrm{mlU} / \mathrm{ml})$ & $6.75 \pm 1.77$ & $7.04 \pm 2.03$ & $6.88 \pm 1.95$ & $6.57 \pm 1.68$ & 0.063 \\
\hline \multicolumn{6}{|l|}{ Season of blood drawing } \\
\hline Spring $(n, \%)$ & $55,25.5 \%$ & $39,18.6 \%$ & $25,11.8 \%$ & $24,11.4 \%$ & \multirow[t]{4}{*}{$<0.001^{*}$} \\
\hline Summer (n, \%) & $78,36.1 \%$ & $71,33.8 \%$ & $55,26.1 \%$ & $41,19.4 \%$ & \\
\hline Autumn (n, \%) & $22,10.2 \%$ & $43,20.5 \%$ & $76,36.0 \%$ & $74,35.1 \%$ & \\
\hline Winter $(n, \%)$ & $61,28.2 \%$ & $57,27.1 \%$ & $55,26.1 \%$ & $72,34.1 \%$ & \\
\hline \multicolumn{6}{|l|}{ Previous pregnancy } \\
\hline $\mathrm{NO}(\mathrm{n}, \%)$ & $106(49.1 \%)$ & $87(41.4 \%)$ & $111(52.6 \%)$ & $103(48.8 \%)$ & \multirow[t]{2}{*}{0.134} \\
\hline Yes $(n, \%)$ & $110(50.9 \%)$ & $123(58.6 \%)$ & $100(47.4 \%)$ & $108(51.2 \%)$ & \\
\hline \multicolumn{6}{|l|}{ Infertility diagnosis } \\
\hline Male factor $(n, \%)$ & $5(2.3 \%)$ & $11(5.2 \%)$ & $10(4.7 \%)$ & $10(4.7 \%)$ & \multirow[t]{6}{*}{0.837} \\
\hline Tubal factor $(n, \%)$ & $135(62.8 \%)$ & $131(62.4 \%)$ & $122(57.8 \%)$ & $125(59.2 \%)$ & \\
\hline Mixed $(n, \%)$ & $24(11.2 \%)$ & $28(13.3 \%)$ & $26(12.3 \%)$ & $28(13.3 \%)$ & \\
\hline Endometriosis $(n, \%)$ & $7(3.3 \%)$ & $11(5.2 \%)$ & $13(6.2 \%)$ & $14(6.6 \%)$ & \\
\hline Anovulatory $(n, \%)$ & $41(19.1 \%)$ & $27(12.9 \%)$ & $37(17.5 \%)$ & $32(15.2 \%)$ & \\
\hline Unexplained $(n, \%)$ & $3(1.4 \%)$ & $2(1.0 \%)$ & $3(1.4 \%)$ & $2(0.9 \%)$ & \\
\hline \multicolumn{6}{|l|}{$\mathrm{COH}$ protocol } \\
\hline Luteal phase agonist $(n, \%)$ & $151(69.9 \%)$ & $143(68.1 \%)$ & $159(75.4 \%)$ & $158(74.9 \%)$ & \multirow[t]{2}{*}{0.250} \\
\hline Antagonist $(n, \%)$ & $65(30.1 \%)$ & $67(31.9 \%)$ & $52(24.6 \%)$ & $53(25.1 \%)$ & \\
\hline Duration of stimulation (d) & $9.06 \pm 2.17$ & $9.04 \pm 2.34$ & $8.81 \pm 2.20$ & $9.05 \pm 2.50$ & 0.631 \\
\hline Follicle $\geq 16 \mathrm{~mm}$ on HCG day & $10.26 \pm 4.94$ & $9.01 \pm 4.73$ & $9.86 \pm 5.55$ & $9.68 \pm 5.02$ & 0.083 \\
\hline Endometrial thickness on HCG day (mm) & $11.62 \pm 2.71$ & $11.30 \pm 2.21$ & $11.36 \pm 2.32$ & $11.49 \pm 2.45$ & 0.536 \\
\hline Progestrone on HCG day (ng/ml) & $0.86 \pm 0.28$ & $0.90 \pm 0.29$ & $0.94 \pm 0.34$ & $0.94 \pm 0.32$ & 0.143 \\
\hline Peak estradiol (pg/ml) & $3737.49 \pm 2178.84$ & $3398.98 \pm 2227.44$ & $3593.33 \pm 2352.79$ & $3569.79 \pm 2231.67$ & 0.540 \\
\hline Oocytes retrieved $(n)$ & $11.47 \pm 5.53$ & $10.12 \pm 4.78$ & $10.79 \pm 5.43$ & $10.68 \pm 5.56$ & 0.078 \\
\hline Mature oocytes (n) & $9.45 \pm 4.80$ & $8.40 \pm 4.14$ & $9.05 \pm 4.66$ & $8.97 \pm 4.54$ & 0.119 \\
\hline Normal fertilization rate (\%) & $69.62 \pm 17.85$ & $71.69 \pm 19.92$ & $73.82 \pm 18.36$ & $75.43 \pm 17.39$ & $0.007^{*}<0.001^{\mathrm{a}^{*}}$ \\
\hline High quality embryo rate (\%) & $67.5 \%$ & $67.2 \%$ & $65.3 \%$ & $67.7 \%$ & 0.465 \\
\hline Blastocyst formation rate (\%) & $66.86 \pm 28.60$ & $62.48 \pm 33.21$ & $65.84 \pm 31.27$ & $67.96 \pm 28.87$ & 0.332 \\
\hline Embryos transferred $(n)$ & $1.93 \pm 0.26$ & $1.92 \pm 0.28$ & $1.97 \pm 0.18$ & $1.95 \pm 0.22$ & 0.340 \\
\hline
\end{tabular}

*Values are significantly different between groups $(P<0.05)$

${ }^{a}$ Adjusted for maternal age, $\mathrm{BMI}, \mathrm{AMH}$, infertility diagnosis, season of blood draw, $\mathrm{COH}$ protocol, previous pregnancy, duration of stimulation, $\mathrm{E} 2$ levels on the day of hCG, number of larger follicles, number of oocytes retrieved and number of mature oocytes 
vitamin $\mathrm{D}$ were inversely related to $\mathrm{BMI}$ and $\mathrm{AMH}$, though this difference was not statistically significant ( $p=0.099$ and $p=0.134$, respectively). $25(\mathrm{OH}) \mathrm{D}$ concentrations were significantly related to seasons when the samples were taken $(P<0.001)$. Serum $25(\mathrm{OH}) \mathrm{D}$ levels were higher in autumn than other seasons, and the lowest level occured in spring (Additional file 1: Table S1). Vitamin D status was not associated with age, infertility diagnosis, duration of infertility, previous pregnancy, stimulation protocol, ovarian stimulation parameters (duration of stimulation, peak estradiol levels, progesterone on HCG day, endometrial thickness or number of mature oocytes, as noted in Table 1), high quality embryo rate, blastocyst formation rate or number of embryos transferred $(\mathrm{p}>0.05) .25(\mathrm{OH}) \mathrm{D}$ concentrations were inversely related to the number of larger follicles $(\geq 16 \mathrm{~mm}$ on HCG day) and number of oocytes, though this difference was not statistically significant $(p=0.083$ and $p=$ 0.078 , respectively). However, the levels of vitamin D were positively related to normal fertilization rates $(p=0.007)$. A similar relationship was observed between vitamin $\mathrm{D}$ status and the fertilization rates $(P<0.001)$ after adjusting for potential confounders (age, BMI, AMH, type of infertility, previous pregnancy, seasons when sample were taken, the type of treatment protocol, duration of stimulation, $E_{2}$ levels on the day of hCG, number of larger follicles, number of oocytes retrieved and number of mature oocytes).

To further determine the effect of vitamin D on fertilization, we compared vitamin D levels in patients treated with IVF and R-ICSI. We found that serum vitamin $\mathrm{D}$ levels were significantly higher in patients treated with IVF than R-ICSI $(p=0.013)$ (Fig. 2). In addition, we observed the relationship of follicular fluid vitamin D levels and serum vitamin D levels.

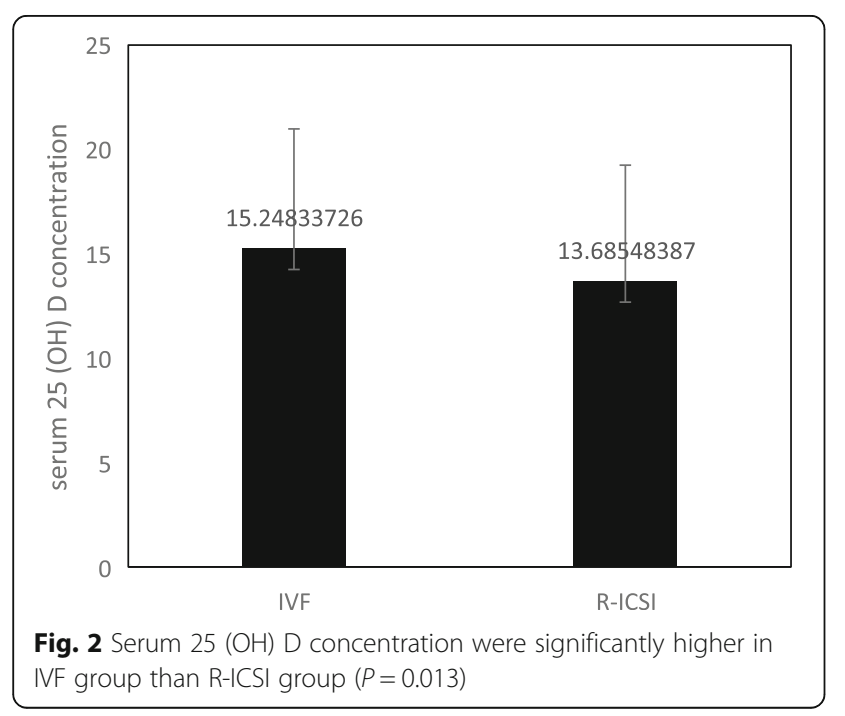

The results showed that FF vitamin D levels were positively correlated with serum vitamin D levels $(r=$ $0.85, p<0.001)$. The levels of FF vitamin D were significantly higher than the levels of serum vitamin $D$ $(P<0.001)$ (Fig. 3).

Table 2 depicts the patient and IVF cycle characteristics by pregnancy outcome. Live birth was associated with age $(P<0.001)$, stimulation protocol $(p=0.027)$, endometrial thickness $(P=0.002)$, number of oocytes retrieved $(p=0.02)$, number of mature oocytes $(p=0.024)$ and high quality embryo rate $(p=0.001)$. AMH, peak estradiol, number of larger follicles and embryos transferred were greater in the live birth group, but they did not achieve statistical significance. Only age $(P<0.001)$ and endometrial thickness $(P=0.008)$ were significantly

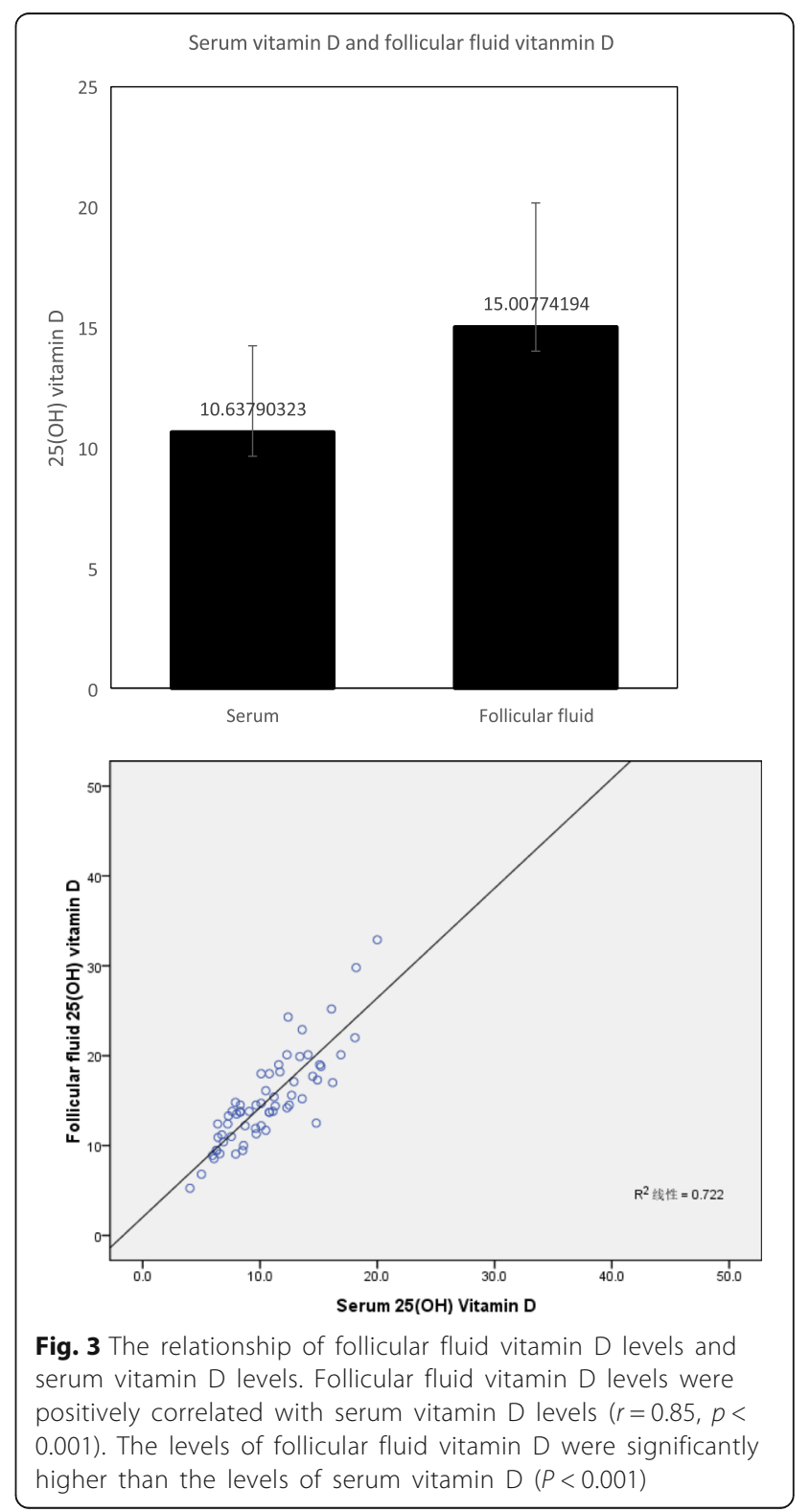


Table 2 Patients and IVF cycle characteristics by pregnancy outcome

\begin{tabular}{|c|c|c|c|c|c|c|}
\hline Parameter & Pregnant & Not pregnant & $P$ value & Live birth & No live birth & $P$ value \\
\hline Number of cycles & 293 & 194 & & 261 & 226 & \\
\hline Age(y) & $31.29 \pm 3.53$ & $32.63 \pm 3.65$ & $<0.001^{*}$ & $31.12 \pm 3.41$ & $32.64 \pm 3.71$ & $<0.001^{*}$ \\
\hline Duration of infertility(y) & $3.54 \pm 2.26$ & $3.77 \pm 2.43$ & 0.284 & $3.45 \pm 2.15$ & $3.84 \pm 2.52$ & 0.065 \\
\hline $\mathrm{BMI}\left(\mathrm{kg} / \mathrm{m}^{2}\right)$ & $23.25 \pm 3.34$ & $23.74 \pm 3.46$ & 0.116 & $23.28 \pm 3.34$ & $23.62 \pm 3.46$ & 0.271 \\
\hline $\mathrm{AMH}(\mathrm{ng} / \mathrm{ml})$ & $5.31 \pm 3.76$ & $4.83 \pm 3.55$ & 0.160 & $5.41 \pm 3.82$ & $4.79 \pm 3.50$ & 0.065 \\
\hline bFSH (mIU/ml) & $6.98 \pm 1.74$ & $7.10 \pm 1.88$ & 0.475 & $6.93 \pm 1.74$ & $7.14 \pm 1.87$ & 0.208 \\
\hline \multicolumn{7}{|l|}{ Season of blood drawing } \\
\hline Spring $(n, \%)$ & $41,54.7 \%$ & $34,45.3 \%$ & 0.209 & $37,14.2 \%$ & $4,12.5 \%$ & 0.706 \\
\hline Summer $(n, \%)$ & $\begin{array}{l}83 \\
58.5 \%\end{array}$ & $59,41.5 \%$ & & $76,29.1 \%$ & $7,21.9 \%$ & \\
\hline Autumn $(n, \%)$ & $83,68.0 \%$ & $39,32.0 \%$ & & $74,28.4 \%$ & $9,28.1 \%$ & \\
\hline Winter $(n, \%)$ & $86 ; 58.1 \%$ & $62,41.9 \%$ & & $74,28.4 \%$ & $12,37.5 \%$ & \\
\hline \multicolumn{7}{|l|}{ Previous pregnancy } \\
\hline $\mathrm{NO}(n, \%)$ & $141,48.1 \%$ & $89,45.9 \%$ & 0.628 & $129,49.4 \%$ & $106,46.9 \%$ & 0.587 \\
\hline Yes $(n, \%)$ & $152,51.9 \%$ & $105,54.1 \%$ & & $132,50.6 \%$ & $120,53.1 \%$ & \\
\hline \multicolumn{7}{|l|}{ Infertility diagnosis } \\
\hline Male factor $(n, \%)$ & $11,3.8 \%$ & $6,3.1 \%$ & 0.426 & $10,3.8 \%$ & $6,2.7 \%$ & 0.688 \\
\hline Tubal factor ( $n, \%)$ & $193,65.9 \%$ & $125,64.4 \%$ & & $168,64.4 \%$ & $150,66.4 \%$ & \\
\hline Mixed $(n, \%)$ & $41,14.0 \%$ & $21,10.8 \%$ & & $38,14.6 \%$ & $25,11.1 \%$ & \\
\hline Endometriosis $(n, \%)$ & $18,6.1 \%$ & $11,5.7 \%$ & & $16,6.1 \%$ & $12,5.3 \%$ & \\
\hline Anovulatory $(n, \%)$ & $28,9.6 \%$ & $27,13.9 \%$ & & $26,10.0 \%$ & $29,12.8 \%$ & \\
\hline Unexplained $(n, \%)$ & $2,0.7 \%$ & $4,2.1 \%$ & & $3,1.1 \%$ & $4,1.8 \%$ & \\
\hline \multicolumn{7}{|l|}{$\mathrm{COH}$ protocol } \\
\hline Luteal phase agonist $(n, \%)$ & $228,77.8 \%$ & $138,71.1 \%$ & 0.108 & $207,79.3 \%$ & $159,70.4 \%$ & $0.027^{*}$ \\
\hline Antagonist $(n, \%)$ & $65,22.2 \%$ & $56,28.9 \%$ & & $54,20.7 \%$ & $67,29.6 \%$ & \\
\hline Duration of stimulation (d) & $9.08 \pm 2.31$ & $9.05 \pm 2.06$ & 0.908 & $9.06 \pm 2.26$ & $9.07 \pm 2.16$ & 0.962 \\
\hline Follicle $\geq 16 \mathrm{~mm}$ on HCG day & $7.74 \pm 3.04$ & $7.22 \pm 2.96$ & 0.059 & $7.78 \pm 2.90$ & $7.25 \pm 3.13$ & 0.055 \\
\hline Endometrial thickness on HCG day (mm) & $11.75 \pm 2.10$ & $11.22 \pm 2.24$ & $0.008^{*}$ & $11.82 \pm 2.09$ & $11.21 \pm 2.22$ & $0.002^{*}$ \\
\hline Progestrone on HCG day (ng/ml) & $0.92 \pm 0.29$ & $0.90 \pm 0.33$ & 0.578 & $0.92 \pm 0.29$ & $0.90 \pm 0.33$ & 0.332 \\
\hline Peak estradiol (pg/ml) & $2602.72 \pm 1142.74$ & $2436.73 \pm 1032.56$ & 0.116 & $2625.10 \pm 1114.09$ & $2436.06 \pm 1078.48$ & 0.070 \\
\hline Oocytes retrieved $(n)$ & $8.39 \pm 2.98$ & $7.91 \pm 3.28$ & 0.094 & $8.50 \pm 2.95$ & $7.85 \pm 3.25$ & $0.020^{*}$ \\
\hline Mature oocytes (n) & $7.03 \pm 2.68$ & $6.66 \pm 2.99$ & 0.156 & $7.15 \pm 2.68$ & $6.58 \pm 2.92$ & $0.024^{*}$ \\
\hline Normal fertilization rate (\%) & $72.55 \pm 17.70$ & $73.19 \pm 20.05$ & 0.710 & $72.22 \pm 17.18$ & $73.48 \pm 20.23$ & 0.456 \\
\hline High quality embryo rate (\%) & $59.5 \%$ & $57.1 \%$ & 0.199 & $58.4 \%$ & $51.6 \%$ & $0.001^{*}$ \\
\hline Blastocyst formation rate (\%) & $66.33 \pm 31.39$ & $62.75 \pm 34.51$ & 0.273 & $66.06 \pm 31.59$ & $63.61 \pm 33.90$ & 0.443 \\
\hline Embryos transferred $(n)$ & $1.96 \pm 0.21$ & $1.92 \pm 0.28$ & 0.082 & $1.96 \pm 0.20$ & $1.92 \pm 0.27$ & 0.081 \\
\hline
\end{tabular}

*Values are significantly different between groups $(P<0.05)$

associated with clinical pregnancy. The number of larger follicles, oocytes and embryos transferred were higher in the clinical pregnancy group, but they did not achieve statistical significance.

As shown in Table 3, serum $25(\mathrm{OH})$ D levels were not related to clinical pregnancy rates, implantation rates, abortion rates and live birth rates. Results though were similar after adjusting for potential confounding factors (age, BMI, AMH, type of infertility, previous pregnancy, seasons when samples were taken, the type of treatment protocol, duration of stimulation, number of oocytes retrieved, endometrial thickness, serum progesterone levels on the day of hCG and the number of embryo transferred). 
Table 3 Serum $25(\mathrm{OH})$ D concentrations in relation to clinical outcomes of IVF: univariate and multivariate logistic analysis

\begin{tabular}{|c|c|c|c|c|}
\hline Outcomes & Group1 & Group2 & Group 3 & Group 4 \\
\hline Number of cycles & 216 & 210 & 211 & 211 \\
\hline Clinical pregnancy rate (\%) & $59.2 \%$ & $57.9 \%$ & $60.0 \%$ & $63.5 \%$ \\
\hline Univariate $(\mathrm{OR}(95 \% \mathrm{Cl}), \mathrm{P})$ & 1 & $0.947(0.567-1.581), 0.836$ & $1.035(0.618-1.734), 0.895$ & $1.200(0.718-2.006), 0.486$ \\
\hline Multivariate $^{\mathrm{a}}(\mathrm{OR}(95 \% \mathrm{Cl}), \mathrm{P})$ & 1 & $1.007(0.578-1.752), 0.981$ & $0.988(0.562-1.737), 0.968$ & $1.173(0.674-2.043), 0.573$ \\
\hline Implantation rate (\%) & $42.9 \%$ & $41.4 \%$ & $44.5 \%$ & $43.9 \%$ \\
\hline Univariate $(\mathrm{OR}(95 \% \mathrm{Cl}), \mathrm{P})$ & 1 & $0.941(0.651-1.361), 0.747$ & $1.069(0.741-1.541), 0.722$ & $1.043(0.726-1.499), 0.818$ \\
\hline Multivariate $^{a}(\mathrm{OR}(95 \% \mathrm{Cl}), \mathrm{P})$ & 1 & $0.958(0.647-1.419), 0.931$ & $1.024(0.690-1.518), 0.907$ & $1.021(0.693-1.506), 0.915$ \\
\hline Abortion rate (\%) & $8.5 \%$ & $10.0 \%$ & $2.8 \%$ & $8.8 \%$ \\
\hline Univariate $(\mathrm{OR}(95 \% \mathrm{Cl}), \mathrm{P})$ & 1 & $1.398(0.459-4.260), 0.556$ & $0.637(0.172-2.362), 0.500$ & $1.373(0.463-4.070), 0.567$ \\
\hline Multivariate $^{a}(\mathrm{OR}(95 \% \mathrm{Cl}), \mathrm{P})$ & 1 & $1.319(0.365-4.768), 0.673$ & $0.732(0.171-3.126) 0.673$ & $1.302(0.373-4.544), 0.679$ \\
\hline Live birth rate (\%) & $53.3 \%$ & $48.8 \%$ & $56.7 \%$ & $55.6 \%$ \\
\hline Univariate $(\mathrm{OR}(95 \% \mathrm{Cl}), \mathrm{P})$ & 1 & $0.833(0.502-1.381), 0.478$ & $1.144(0.688-1.903), 0.604$ & $1.094(0.662-1.807), 0.726$ \\
\hline Multivariate $^{\mathrm{a}}(\mathrm{OR}(95 \% \mathrm{Cl}), \mathrm{P})$ & 1 & $0.876(0.507-1.515), 0.636$ & $1.089(0.624-1.901), 0.765$ & $1.078(0.626-1.856), 0.787$ \\
\hline
\end{tabular}

Values are significantly different between groups $(P<0.05)$

${ }^{a}$ Adjusted for maternal age, BMI, AMH, type of infertility, previous pregnancy, seasons when samples were taken, $\mathrm{COH}$ protocol, duration of stimulation, number of oocytes retrieved, endometrial thickness, serum progesterone levels on the day of hCG and the number of embryo transferred

The predictive value of vitamin $\mathrm{D}$ regarding normal fertilization rate, pregnancy rate and live birth rate were analyzed by ROC curve (Fig. 4). After analyzing the ROC curve, optimal sensitivity and specificity at the cutoff point $(14.1 \mathrm{ng} / \mathrm{ml})$ were found to be 49.8 and $85.7 \%$ for the fertilization rate. The area under the ROC curve for vitamin D was 0.674 $(p=0.0007)$. However, for pregnancy rate and birth rate, the area under the ROC curve was 0.521 and 0.523 respectively, demonstrating poor performance for the prediction of pregnancy and live birth.

\section{Discussion}

In this large retrospective cross-sectional study, 848 women underwent 848 IVF cycles. The serum $25(\mathrm{OH})$ D concentrations were between 4.92 and $39.51 \mathrm{ng} / \mathrm{ml}$. The median $25(\mathrm{OH})$ D concentration was $15.25 \mathrm{ng} / \mathrm{ml}$. Serum vitamin D levels significantly vary in different seasons because of the different exposure to sunlight. Serum $25(\mathrm{OH})$ D levels were higher in autumn than other seasons, and the lowest level occurred in spring (Additional file 1: Table S1).

This study investigated the association between vitamin D and outcomes of IVF. Our results indicate that vitamin $\mathrm{D}$ was positively related to normal fertilization rate. Women in the highest quartile of vitamin D had a $5.81 \%$ higher normal fertilization rate than women in the lowest quartile. Moreover, serum vitamin D levels were significantly lower in patients treated with R-ICSI than those with IVF. FF vitamin D levels were positively correlated with serum vitamin D levels and were significantly higher than the levels of serum vitamin D. Therefore, we believe that vitamin $\mathrm{D}$ can affect fertilization. However, the role of vitamin D in fertilization remains unclear. As we all know, the process of fertilization includes two key steps: the interaction and penetration of the sperm to the zona pellucida, the fusion of the sperm and the oocyte membranes and triggering oocyte activation. In this study, we found these oocytes could be actived and could form embryos after RICSI. Therefore, vitamin D could affect fertilization by altering the capacity of interaction and penetration of the zona pellucid by the sperm. Some researchers found that vitamin $D$ had effect on the development of follicle [24]. It may have been speculated that more $25(\mathrm{OH}) \mathrm{D}$ are responsive to improve oocytes to reach a more mature stage prior to oocyte retrieval, resulting in a greater capability to achieve fertilization by improving the sperm interaction and penetration of the zona pellucida.

Our result of a positive relationship of vitamin D and normal fertilization rates is in accordance with previous works [33, 34]. In contrast, two studies showed an inverse association between $25(\mathrm{OH}) \mathrm{D}$ and fertilization rates among women undergoing infertility treatment $[26,35]$. However, these data of Aleyasin et al., are difficult to explain in the Iranian study because all participants were vitamin D deficient, except for one [26]. Though serum and FF vitamin D are strongly related to each other (Fig. 3, [26]), Ciepiela et al., evaluated vitamin D levels only from the dominant follicle [35]. Moreover, the sample size of the study was very small [35].

In addition, the levels of vitamin $\mathrm{D}$ were inversely related to BMI, AMH, peak estradiol levels, the number of larger follicles and oocytes, though this difference was not statistically significant in our study. There was a trend for worsening vitamin $\mathrm{D}$ status with increasing $\mathrm{AMH}$, causing the increase of large follicle and oocytes. FF vitamin D levels 


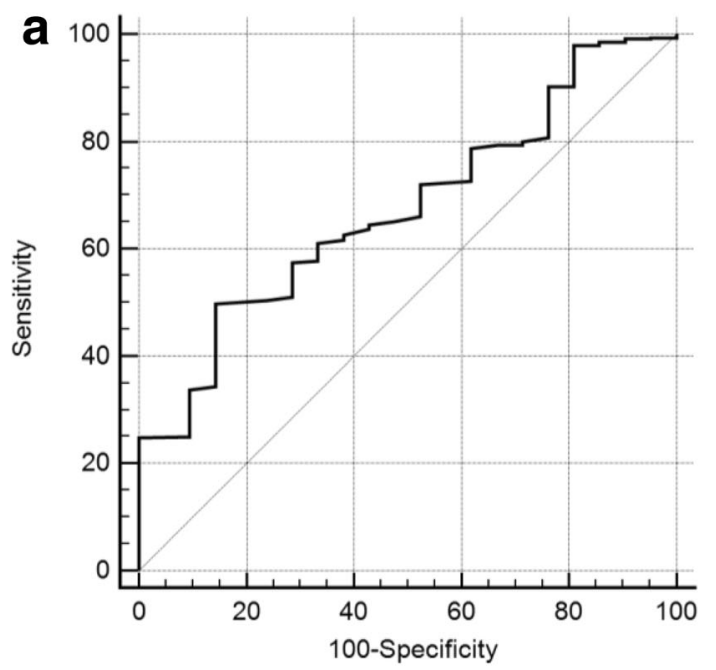

Fig. 4 ROC curve and performance characteristics for total serum vitamin $\mathrm{D}$ measured in patients. a (normal fertilization rate): The area under the ROC curve for vitamin D was 0.674, $p=0.0007$. b (clinical repgnancy rate): The area under the $\mathrm{ROC}$ curve for vitamin $\mathrm{D}$ was $0.521, p=0.4251$. $\mathbf{c}$ (live birth rate): The area under the ROC curve for vitamin $\mathrm{D}$ was $0.523, p=0.3822$

were positively correlated with serum vitamin D levels. Recently, Antunes et al., showed similar results. Specifically, they found that lower FF vitamin D concentrations indicated a better response to ovarian stimulation shown by a greater production of larger follicles and higher serum estradiol concentrations [36]. Furthermore, FF $25(\mathrm{OH})$ D levels were negatively correlated with $\mathrm{AMH}$ and $\mathrm{AMH}$ receptor (AMHR)-II mRNA levels in cumulus granulosa cells (GCs) [37]. Compared with women with sufficient FF 25 $(\mathrm{OH}) \mathrm{D}$ levels, those with insufficient/deficient levels had a 2-fold increase in AMHR-II mRNA levels in cumulus GCs.

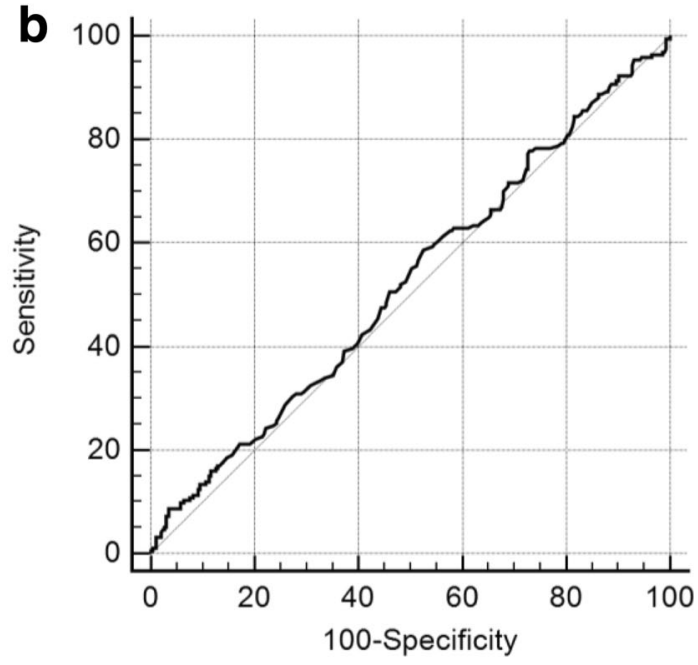
Treatment with vitamin D3 caused a decrease in AMHR-II [37]. These data suggest that vitamin D alters AMH signaling in human cumulus GCs and plays a role in follicle development.

Our study suggests that there were no association between serum $25(\mathrm{OH})$ D and clinical pregnancy or live birth. This is in agreement with the majority of studies [26-30, 33]. However, others have reported positive [17-24] as well as inverse associations [25, 35] between $25(\mathrm{OH}) \mathrm{D}$ and clinical pregnancy. Therefore, whether vitamin D has a role in the outcomes of ART requires further random cohort studies to clarify. Perhaps a prospective randomized control trial would be able to remove biases and give stronger answers.

Even if our study is retrospective, there are still several strengths. The primary strength is the large number of participants. There were only 59-202 patients in previ-

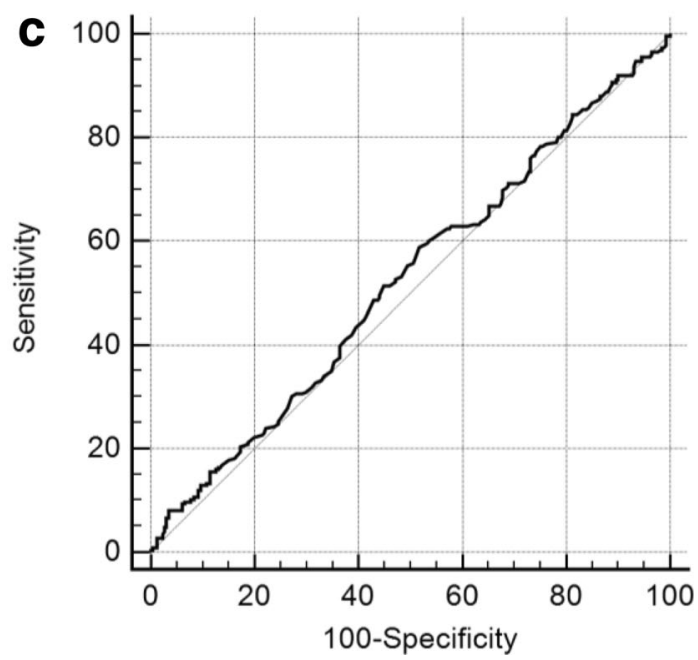
ous reports [19, 25, 26, 33-36], while we observed 848 patients. Furthermore, the population in our study was homogeneous. They were all of Chinese origin. In previous papers, the population was various including Iranian [26, 27], Greek [25] and highly diverse American patients [19]. In this study, race is relevant, since it affects the relationship between vitamin D status and pregnancy rates after IVF [17]. Another strength of this study is that we excluded couples with moderate and severe male factor. We evaluated only patients undergoing IVF to minimize the role of spermatozoa affecting embryo development. In contrast, in some studies, the indications for IVF/ ICSI were not mentioned in papers [19, 25, 26]. While in other studies, $58-65 \%$ of couples had male factor [27].

Some limitations of this study must be considered though. Firstly, this study is a retrospective observational study, we cannot exclude all confounding factors. However, we adjusted the potential confounding factors for a 
wide range to provide reassurance of the validity of our findings. Secondly, we did not measure the vitamin D levels of couples, since serum $25(\mathrm{OH})$ D correlates within the partners of infertile couples [38]. Moreover, we excluded couples with moderate and severe male factor and evaluated only patients undergoing IVF to minimize the role of spermatozoa affecting embryo development. Thirdly, we did not measure the vitamin $\mathrm{D}$ levels at the same points of IVF cycle. However, we evaluated vitamin D levels before entering the IVF cycle. To prevent confounders, women whose plasma total 25 $(\mathrm{OH}) \mathrm{D}$ measurement exceeded 4 weeks prior to entering their IVF cycle were excluded from the study.

\section{Conclusions}

In summary, we found that vitamin $\mathrm{D}$ was positively related to fertilization rate. However, vitamin D was unrelated to clinical pregnancy or live birth in this retrospective cohort study. In this study, patients had serum $25(\mathrm{OH})$ D concentrations between 4.92 and $39.51 \mathrm{ng} / \mathrm{ml}$. FF vitamin D levels were positively correlated with serum vitamin D levels. The levels of FF vitamin D were significantly higher than the levels of serum vitamin $\mathrm{D}$. The relationship of vitamin $\mathrm{D}$ and outcomes of ART should be studied in future large randomized controlled trials.

\section{Additional file}

Additional file 1: Table S1. Patients characteristics in four seasons. (DOCX $16 \mathrm{~kb})$

\section{Abbreviations}

$25(\mathrm{OH})$ D: 25-hydroxyvitamin D; AMH: Anti-Mullerian hormone; ART: Assisted reproductive technologies; BMI: Body mass index; $\mathrm{COH}$ : Controlled ovarian hyperstimulation; ICSI: Intracytoplasmic sperm injection; IVF: In vitro fertilization

\section{Acknowledgements}

This study design was supported by Kun Qian. He is an associate professor at reproductive medicine center of Tongji Hospital. The authors are very grateful to Mrs. Elena Linara-Demakakou for the corrections of language. She is a deputy laboratory manager, quality lead and senior embryologist at London Women's Clinic.

\section{Authors' contributions}

$X L$ and $W Z$ were involved in the design of the study, drafted and revision of intellectual content of the manuscript. $X L, W Z, Y X, Y W$ and $Z L$ analyzed data. $Y X, Z M, Y C, X W$ and $Q L$ were involved in the critical revision of the manuscript. All authors approved the final version for submission.

\section{Funding}

This work was supported by National Natural Science Foundation of China (81601276) and the special fund for clinical research of the Chinese Medical Association (16020220638).

Availability of data and materials

The primary data for this study is available from patient medical records.
Ethics approval and consent to participate

The study was approved by the Ethical Committee of Yantai Yuhuangding Hospital.

\section{Consent for publication}

Not applicable.

\section{Competing interests}

The authors declare that they have no competing interests.

\section{Author details}

${ }^{1}$ Reproductive Medicine Center, Yantai Yuhuangding Hospital, Affiliated Hospital of Qingdao University, Yantai, Shandong, China. 'Department of Obstetrics and Gynecology, Yantai Yuhuangding Hospital, Affiliated Hospital of Qingdao University, Yantai, Shandong, China. ${ }^{3}$ Scientific Research Office, Yantai Yuhuangding Hospital, Affiliated Hospital of Qingdao University, Yantai, Shandong, China.

Received: 6 May 2019 Accepted: 5 July 2019

Published online: 18 July 2019

\section{References}

1. Panda DK, Miao D, Tremblay ML, Sirois J, Farookhi R, Hendy GN, Goltzman D. Targeted ablation of the 25-hydroxyvitamin D 1 alpha-hydroxylase enzyme: evidence for skeletal, reproductive, and immune dysfunction. Proc Natl Acad Sci U S A. 2001;98:7498-503.

2. Holick MF. Vitamin D deficiency. N Engl J Med. 2007;357:266-81.

3. Looker AC, Pfeiffer CM, Lacher DA, Schleicher RL, Picciano MF, Yetley EA. Serum 25-hydroxyvitamin D status of the US population: 1988-1994 compared with 2000-2004. Am J Clin Nutr. 2008:88:1519-27.

4. Hossein-Nezhad A, Holick MF. Vitamin D for health: a global perspective. Mayo Clin Proc. 2013;88:720-55.

5. Adami S, Romagnoli E, Carnevale V, Scillitani A, Giusti A, Rossini M, et al. Guidelines on prevention and treatment of viatmin D deficency. Reumatismo. 2011:63:129-47.

6. Rosen CJ, Adams JS, Bikle DD, Black DM, Demay MB, Manson JE, et al. The nonskeletal effects of vitamin D: an Endocrine Society scientific statement. Endocr Rev. 2012;33:456-92.

7. Tangpricha V, Pearce EN, Chen TC, Holick MF. Vitamin D insufficiency among free-living healthy young adults. Am J Med. 2002;112:659-62.

8. Gordon CM, DePeter KC, Feldman HA, Grace E, Emans SJ. Prevalence of vitamin D deficiency among healthy adolescents. Arch Pediatr Adolesc Med. 2004;158:531-7.

9. Sullivan SS, Rosen CJ, Halteman WA, Chen TC, Holick MF. Adolescent girls in Maine are at risk for vitamin D insufficiency. J Am Diet Assoc. 2005;105:971-4.

10. Johnson LE, Deluca HF. Vitamin D receptor null mutant mice fed high levels of calcium are fertile. J Nutr. 2001;131:1787-91.

11. Halloran BP, DeLuca HF. Effect of vitamin D deficiency on fertility and reproductive capacity in the female rat. J Nutr. 1980;110:1573-80.

12. Kinuta K, Tanaka H, Moriwake T, Aya K, Kato S, Seino Y. Vitamin D is an important factor in estrogen biosynthesis of both female and male gonads. Endocrinology. 2000;141:1317-24.

13. Yoshizawa Y, Handa Y, Uematsu Y, Takeda S, Sekine K, Yoshihara Y, et al. Mice lacking the vitamin $D$ receptor exhibit impaired bone formation, uterine hypoplasia and growth retardation after weaning. Nat Genet. 1997;16:391-6.

14. Aghajafari F, Nagulesapillai T, Ronksley PE, Tough SC, O'Beirne M, Rabi DM. Association between maternal serum 25-hydroxyvitamin D level and pregnancy and neonatal outcomes: systematic review and meta-analysis of observational studies. BMJ. 2013;346:f1169.

15. Laganà AS, Vitale SG, Ban Frangež H, Vrtačnik-Bokal E, D'Anna R. Vitamin D in human reproduction: the more, the better? An evidence-based critical appraisal. Eur Rev Med Pharmacol Sci. 2017;21:4243-51.

16. Anagnostis P, Karras $S$, Goulis DG. Vitamin D in human reproduction: a narrative review. Int J Clin Pract. 2013;67:225-35.

17. Rudick B, Ingles S, Chung K, Stanczyk F, Paulson R, Bendikson K. Characterizing the influence of vitamin D levels on IVF outcomes. Hum Reprod. 2012;27:3321-7.

18. Rudick BJ, Ingles SA, Chung K, Stanczyk FZ, Paulson RJ, Bendikson KA. Influence of vitamin $D$ levels on in vitro fertilization outcomes in donor-recipient cycles. Fertil Steril. 2014;101:447-52. 
19. Ozkan S, Jindal S, Greenseid K, Shu J, Zeitlian G, Hickmon C, et al. Replete vitamin $\mathrm{D}$ stores predict reproductive success following in vitro fertilization. Fertil Steril. 2010;94:1314-9.

20. Garbedian K, Boggild M, Moody J, Liu KE. Effect of vitamin D status on clinical pregnancy rates following in vitro fertilization. CMAJ Open. 2013;1:E77-82.

21. Paffoni A, Ferrari S, Viganò P, Pagliardini L, Papaleo E, Candiani M, et al. Vitamin $D$ deficiency and infertility: insights from in vitro fertilization cycles. J Clin Endocrinol Metab. 2014;99:E2372-6.

22. Zhao J, Liu S, Wang Y, Wang P, Qu D, Liu M, et al. Vitamin D improves invitro fertilization outcomes in infertile women with polycystic ovary syndrome and insulin resistance. Minerva Med. 2019;110:199-208.

23. Chu J, Gallos I, Tobias A, Tan B, Eapen A, Coomarasamy A. Vitamin D and assisted reproductive treatment outcome: a systematic review and metaanalysis. Hum Reprod. 2018;33:65-80.

24. Zhao J, Huang $X, X u B$, Yan Y, Zhang $Q$, Li Y. Whether vitamin D was associated with clinical outcome after IVF/ICSI: a systematic review and meta-analysis. Reprod Biol Endocrinol. 2018;16:13.

25. Anifandis GM, Dafopoulos K, Messini Cl, Chalvatzas N, Liakos N, Pournaras S, et al. Prognostic value of follicular fluid 25-OH vitamin D and glucose levels in the IVF outcome. Reprod Biol Endocrinol. 2010;8:91.

26. Aleyasin A, Hosseini MA, Mahdavi A, Safdarian L, Fallahi P, Mohajeri MR, et al. Predictive value of the level of vitamin $D$ in follicular fluid on the outcome of assisted reproductive technology. Eur J Obstet Gynecol Reprod Biol. 2011;159:132-7.

27. Firouzabad RD, Rahmani E, Rahsepar M, Firouzabadi MM. Value of follicular fluid vitamin $D$ in predicting the pregnancy rate in an IVF program. Arch Gynecol Obstet. 2014;289:201-6.

28. Fabris A, Pacheco A, Cruz M, Puente JM, Fatemi H, Garcia-Velasco JA. Impact of circulating levels of total and bioavailable serum vitamin $D$ on pregnancy rate in egg donation recipients. Fertil Steril. 2014;102:1608-12.

29. Franasiak JM, Molinaro TA, Dubell EK, Scott KL, Ruiz AR, Forman EJ, et al. Vitamin D levels do not affect IVF outcomes following the transfer of euploid blastocysts. Am J Obstet Gynecol. 2015;212:315. e1-6.

30. Neville G, Martyn F, Kilbane M, O'Riordan M, Wingfield M, McKenna M, et al. Vitamin D status and fertility outcomes during winter among couples undergoing in vitro fertilization/intracytoplasmic sperm injection. Int J Gynaecol Obstet. 2016;135:172-6.

31. Balaban B, Brison D, Calderón G, Catt J, Conaghan J, Cowan L, et al. The Istanbul consensus workshop on embryo assessment: proceedings of an expert meeting. Hum Reprod. 2011;26:1270-83.

32. Pittaway JK, Ahuja KD, Beckett JM, Bird ML, Robertson IK, Ball MJ. Make vitamin D while the sun shines, take supplements when it doesn't: a longitudinal, observational study of older adults in Tasmania, Australia. PLoS One. 2013;8:e59063.

33. Abadia L, Gaskins AJ, Chiu YH, Williams PL, Keller M, Wright DL, et al. Environment and reproductive health study team. Serum 25-hydroxyvitamin $\mathrm{D}$ concentrations and treatment outcomes of women undergoing assisted reproduction. Am J Clin Nutr. 2016;104:729-35.

34. Cunningham TK, Allgar V, Dargham SR, Kilpatrick E, Sathyapalan T, Maguiness S, et al. Association of Vitamin D metabolites with embryo development and fertilization in women with and without PCOS Undergoing subfertility treatment. Front Endocrinol (Lausanne). 2019;10:13. https://doi.org/10.3389/fendo.2019.00013.

35. Ciepiela P, Dulęba AJ, Kowaleczko E, Chełstowski K, Kurzawa R. Vitamin D as a follicular marker of human oocyte quality and a serum marker of in vitro fertilization outcome. J Assist Reprod Genet. 2018;35:1265-76.

36. Antunes RA, Mancebo ACA, Reginatto MW, Deriquehem VAS, Areas P, Bloise $\mathrm{E}$, et al. Lower follicular fluid vitamin D concentration is related to a higher number of large ovarian follicles. Reprod BioMed Online. 2018;36:277-84.

37. Merhi Z, Doswell A, Krebs K, Cipolla M. Vitamin D alters genes involved in follicular development and steroidogenesis in human cumulus granulosa cells. J Clin Endocrinol Metab. 2014;99:e1137-45.

38. Paffoni A, Ferrari S, Mangiarini A, Noli S, Bulfoni A, Vigano P, et al. Concordance of vitamin $D$ peripheral levels in infertile couples' partners. Gynecol Endocrinol. 2017;33:649-52.

\section{Publisher's Note}

Springer Nature remains neutral with regard to jurisdictional claims in published maps and institutional affiliations.

Ready to submit your research? Choose BMC and benefit from:

- fast, convenient online submission

- thorough peer review by experienced researchers in your field

- rapid publication on acceptance

- support for research data, including large and complex data types

- gold Open Access which fosters wider collaboration and increased citations

- maximum visibility for your research: over $100 \mathrm{M}$ website views per year

At BMC, research is always in progress.

Learn more biomedcentral.com/submissions 